DOI: $10.21625 /$ resourceedings.v1i1.180

\title{
THE FUTURE OF GREEN BUILDING MATERIALS IN EGYPT: A FRAMEWORK FOR ACTION
}

\author{
Mona Azouz ${ }^{1}$ \\ ${ }^{1}$ Housing and Building National Research Center, Giza
}

\author{
Keywords \\ Green Building Materials, \\ Evaluation Criteria for Green \\ Building Materials, Life Cycle \\ Assessment, Green Building \\ Materials Declaration Sheets, \\ Database for Green Building \\ Materials.,
}

\begin{abstract}
Sustainable development has become a significant worldwide concern. The past few years have seen a lot of changes. Some of these affect how we do approach - and how we should approach - environmental issues. Because of their adverse impacts on sustainability, knowledge about building materials became a crucial dimension of green change in building and design.

The problem is that in Egypt there is still no database for green building materials. In spite that there are currently over 120 international green labeling programs for building materials worldwide, they cannot be locally used. This is because of building materials and the way they are extracted, manufactured, used, transported, recycled or disposed of differ from country to country. All these factors result in insufficiency of data $\&$ information on green building materials and those who are involved in the design, construction \& management of building materials are acutely lacking the basic information on materials that would allow them to make constructive changes.

That's why the introduction of a system for specification, assessment \& selection of green building materials is considered to be one of the corner-stones of promoting sustainable green building development in Egypt as an attempt to fulfil Goal 11 of the Sustainable Development Goals developed by the United Nations to make cities inclusive, safe, resilient and sustainable by 2030 .

The aim of the research is to develop a framework for a system for evaluating the sustainability of building materials in Egypt to achieve greener steps towards sustainability with a new way of scoring sustainability of building materials that evaluates both positive \& negative ecological, social \& health and economic impacts through the whole lifecycle. This system could be applied in the development of the New Cites that considers the unique challenges of the region and the local market and could be applied all over the country taking into consideration the nature of each region with its available building materials and specific climatic conditions and the different regional priorities and requirements.
\end{abstract}

The research was based on an inductive approach to studying \& analysis of the life cycle of the building materials, the different aspects and criteria for the evaluation of green building materials, currently available resources of information about building materials in Egypt and the international \& national reference values \& benchmarks that could be used as a base for the new system. 
Findings will lead to a proposed framework of a system for specification and assessment of green building materials in Egypt. This framework describes all the kind of information required and the procedures that should be taken for the development of the system from collecting data till the establishment of online guide for green building materials and a digital library for accessible and reliable information on green building materials that enables building designers, constructors and developers to make reasoned choices based on the health \&

environmental impacts of their decisions and eases the use \& selection of Green Building materials in Egypt over the coming years.

\section{Introduction}

All around the world, there is a growing trend towards sustainability for the sake of the environment \& the human health. In January 2009, a major step was taken towards sustainability in Egypt by establishing the Egyptian Green Building Council (EGBC) \& developing the Green Pyramid Rating System (GPRS) as a tool to encourage the movement towards sustainability in construction. The use of green building materials represents one important strategy in the design of sustainable buildings. That's why local concerns were raised on the availability of information about the environmental, health \& economic impacts of building materials.

In Egypt with the current efforts to shift towards sustainable building practices, the development of a national database for all available green building materials in the local market became a must. An attempt has been made in this paper to propose a framework for the system of developing a national database considering various factors that are essential for sustainable development, based on setting a holistic approach for integrated evaluation criteria for qualifying and certifying green building materials.

\section{Research Objectives}

The aim of the research is to develop a framework for a new system for developing a database for all available green building materials in the local market and creating a methodology to make the process manageable and logical through several steps method. The main goal of developing the database is to help users of building materials to have an access to wider and more comprehensive information concerning different green building materials and to compare and score their real performance \& health, environmental and economic impacts and that by suggesting a new way for scoring, that evaluates the negative and positive impacts of each criterion on the environment, health and economy.

\section{Methodology}

The research is a scientific critical investigation based on an inductive approach through studying \& analysis of the life cycle of green building materials, the different aspects that represent areas of improvement to which the green building material can contribute and the different criteria for the evaluation of building materials. The research also illustrates the issue of the lack of information on green building materials in Egypt and the currently available resources of information about building materials in Egypt and the international \& national reference values \& benchmarks that could be used as a base for the new system. In addition to the illustration of the information required and the procedures that should be taken for the development of the new system that encourages the use of green building materials to achieve greener steps towards sustainability.

\subsection{What is a Green Building Material?}

At present, there seems to be a lot of confusion in defining green materials. The process of determining exactly how green specific materials are is very complicated. The trouble in identifying the truest definition of green may be that there is no absolute definition. The lack of public unity in a definition has caused the meaning to become convoluted and impossible to distinctly pronounce. However, there is a complexity of variables that contribute to the greenness of a material and how to apply these principles in design and building. (Fithian, 2009)

Generally, a Green Building Material could be defined as:

"A green material is one that simultaneously does the most with the least, fits most harmoniously within ecosystem processes, helps eliminate the use of other materials and energy, and contributes to the attainment of a service-based economy". (Milani, 2001)

As long as a material has at least one positive impact on the environment, it could be defined as green. However, when analyzed more carefully, this same material could actually be harming the environment more than it is helping. 


\subsection{The Life Cycle of a Green Building Material}

The stages of a whole life cycle of a green building material from cradle to grave or cradle to cradle are illustrated in Fig.(1) and could be classified into three main stages:

- Manufacturing \& construction stage and this stage includes extraction of raw materials, transportation, manufacturing and construction \& installation.

- In-use stage and this stage includes use \& maintenance.

- End of life stage and this stage includes demolition \& dismantling, transportation, disposal or recycling $\&$ reuse.

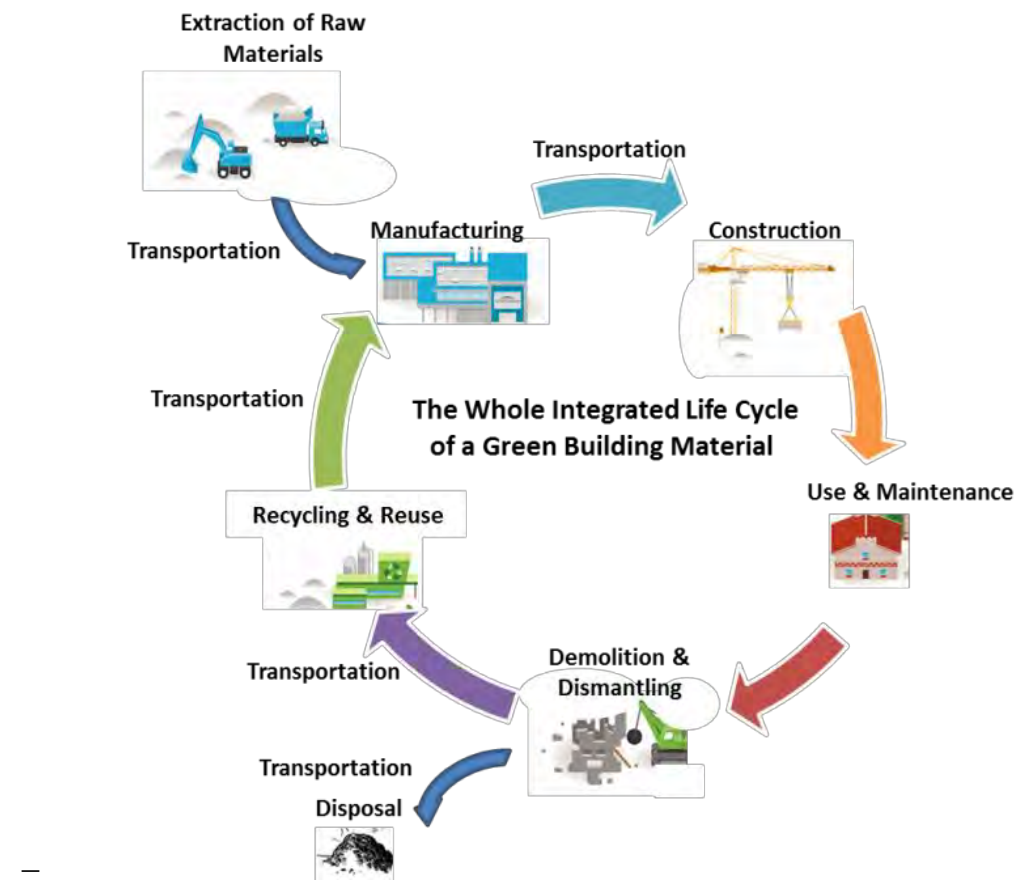

Fig. (1): A Graph Showing the Different Stages of a Whole Integrated Life Cycle of a Green Building Material Source: The Researcher

\section{Aspects that represent areas of improvement to which the green building material can contribute:}

Efficiency of resources: Resource Efficiency can be accomplished by utilizing materials that meet one or more of the following criteria:

- The use of renewable resources: Materials manufactured from/with renewable resources (i.e. certified wood harvested from sustainably managed sources/solar and wind energy) to minimize the negative impact on biodiversity and ecosystems.

- Locally available: Building materials, components and systems found locally or regionally, to minimize the energy spent in transportation to the project site.

- Recycled content in materials and recyclable packaging: Materials that incorporate recycled content (post-consumer and/or postindustrial) or have been recycled from existing or demolished buildings. Products enclosed in recycled content or recyclable packaging.

- Resource efficient process of manufacture: Products manufactured with resource-efficient processes that aim reducing energy consumption, minimizing waste and reducing greenhouse gas emissions.

- Reusable or recyclable: Materials that can be easily dismantled and renovated or repaired then restored to be reused at the end of their use life. Meanwhile the recyclability of the materials is measured by the quantity of materials recovered for re-use after the useful life of materials/products or after demolition of the building.

- Durable: Materials that are long lasting and easily maintained that help in eliminating a costly, damaging and time-consuming process of replacement. 
- Energy Efficiency: Energy Efficiency can be maximized by utilizing materials, components and systems that help reduce energy consumption in buildings which in turn reduce the strain on natural resources.

- Water Conservation: Water Conservation can be obtained by utilizing materials that help reduce water consumption in buildings and landscaped areas, and increase water recycling and reuse.

- Indoor Air Quality: Indoor Air Quality can be enhanced by utilizing materials that promote good indoor air quality and meet one or more of the following criteria:

- Low or non-emissions: Materials that emit few or no Volatile Organic Compounds (VOCs), carcinogens, reproductive toxicants or irritants as demonstrated by the manufacturer through appropriate testing and installed with minimal VOC-producing compounds, or by mechanical attachment methods with no/minimal hazards.

- Moisture resistant: Materials that resist moisture or prevent the growth of biological contaminants on indoor surfaces which in turn minimize the use of chemical agents used to remove these contaminants that could indirectly harm indoor air quality.

- Healthy maintained: Materials that that could be healthy maintained by the use of simple, non-toxic, or low VOC methods and products of cleaning to prevent any harmful emissions that could affect indoor air quality.

- Life-cycle cost (LCC): Materials which their life-cycle costs (LCC) from the production stage till end of life stage are lower or comparable to those of "conventional" materials, or are within a project-defined percentage of the overall budget. (Mehta et al., 2014).

\section{The Process of Green Building Material Assessment}

The process of green building material assessment can be broken into three stages: Research, evaluation, and selection. The most time consuming among the three approaches is research. Evaluation can be similarly complicated and relying on material's data (Umar et al., 2012).

\section{Sources of technical information about building materials in Egypt}

Currently available resources of information about building materials in Egypt are:

- Manufacturers or importers' information such as obtaining material safety data sheets (MSDs) for chemical building materials containing hazardous chemicals.

- Independent manufacturers' research to provide in-depth health and environmental information (First Party Certifications).

- Externally verified industry sector declaration if available (Third Party Certifications especially for imported building materials).

- Direct inquiry from manufacturer using questionnaires.

- Websites.

- Labels and brochures.

\section{International \& national reference values \& benchmarks that could be used as a base for the new system}

It is obvious that the process of recognition of impacts and evaluation of green building materials is ambiguous. Moreover, the international guides for green building materials cannot be applied worldwide as it is very difficult to set evaluation tools which would, in all environments, give satisfactory results. Nevertheless, with sublimation of certain methods and procedures, as well as their modification and extension according to the local needs, it is possible to achieve a satisfactory level of environmental evaluation of building materials.

The Egyptian companies producing chemical building products and exporting their products to the EU countries are obliged to comply with the new requirements of the New Legislative Framework on Registration, Evaluation and Authorization of Chemicals Substances (REACH) which is a new European Community Regulation on chemicals and their safe use. The new law entered into force on 1 June 2007.

Setting reference values \& benchmarks is an important requirement for any ranking system. Approved international reference values \& benchmarks related to human health could be applied worldwide but for that related to the 
manufacturing process, use and all other factors cannot be directly used without being adapted, tested and verified to be locally applied. The following resources could be used for the establishment of reference values and benchmarks:

- Egyptian code to improve energy efficiency in buildings.

- $\quad$ The Green Pyramid Rating system (GPRS).

- The benchmark for indoor air quality for the different pollutants should be based on the World Health Organization (WHO) guidelines.

- The Benchmark for Volatile Organic Compounds (VOC) and Formaldehyde in the indoor air emitted from building materials according to the AgBB scheme existent. The sample should comply with the requirements of the AgBB diagram (28 days) for the indoor use of building product.

- International Organization for Standardization (ISO) standards:

- $\quad$ ISO 14040:2006; ISO 14044:2006; Environmental management Life Cycle Assessment (Principles and framework).

- ISO 14025:2006; Environmental labels and declarations - Type III.

- $\quad$ ISO Technical Specification ISO/TS 21929:2006 for functionality and technical quality.

\section{Research Findings}

Based on the whole life cycle of the building materials and their health and/or environmental attributes and the process of green building material assessment, a framework for the system of developing database for green building materials in Egypt is proposed that considers the lack of information on green building materials in Egypt, regulations, standards, references \& benchmarks for green building materials, in addition, that there is currently no national standard format for providing health and/or environmental details of the building materials in Egypt.

\subsection{The Proposed System for Developing Database for Green Building Materials in Egypt}

The aim of the Proposed System is developing legal mechanisms for developing a national database for all available green building materials in the local market to ensure the availability of all necessary information about green building materials as shown in Fig. (2).

The system requires the registration of all existing building materials in the Egyptian market whether produced or imported. 


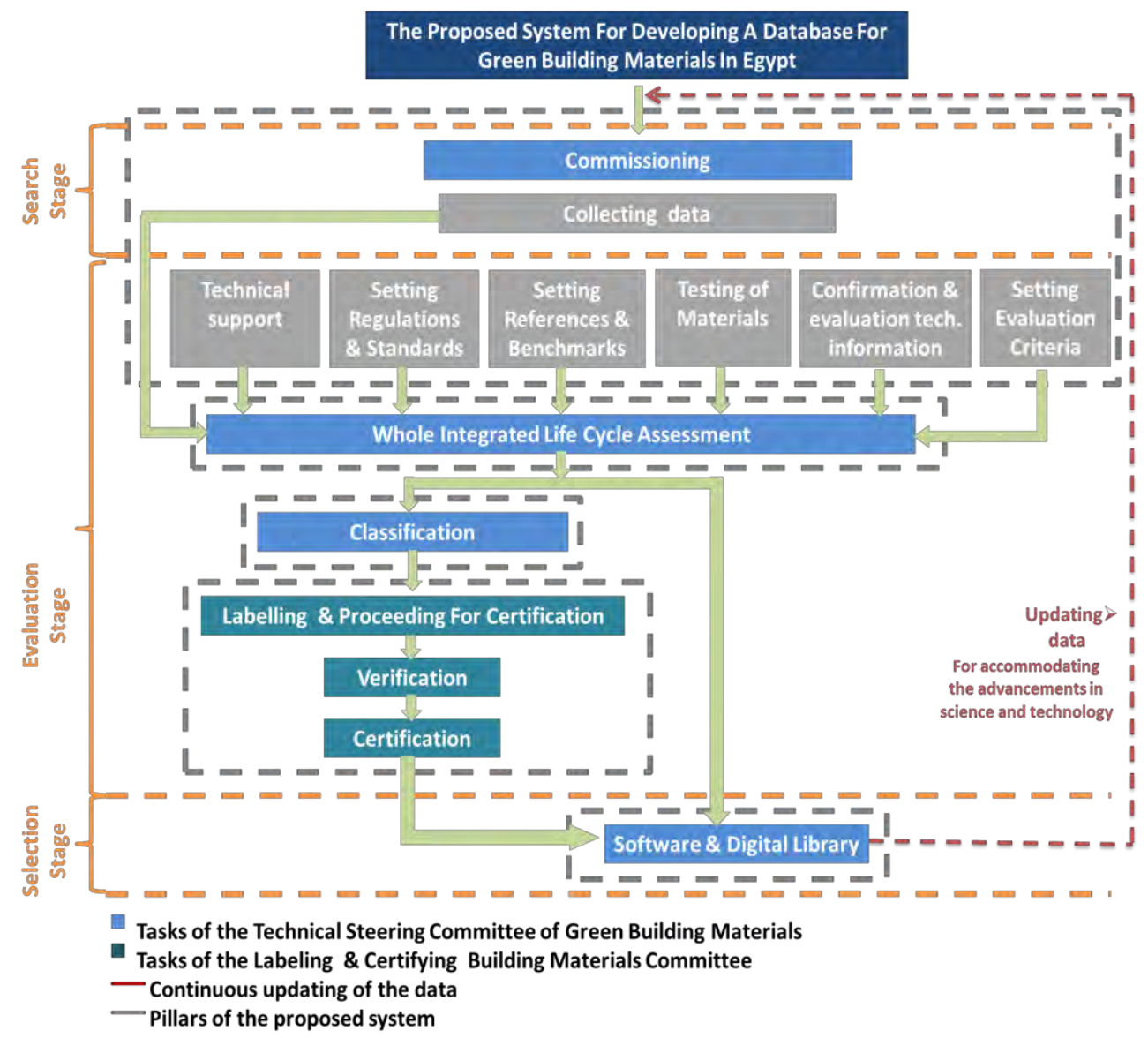

Fig. (2): The Framework for the Proposed System for Developing Database for Green Building Materials in Egypt Source: The Researcher

\subsection{The Structure of the new system}

The proposed system requires the establishment of two new committees as shown in Fig. (3). The Technical Steering Committee of Green Building Materials under the umbrella of Housing \& Building National Research Center and the independent Labelling \& Certifying Building Materials Committee directly under the umbrella of the Ministry of Housing, Utilities \& Urban Communities.

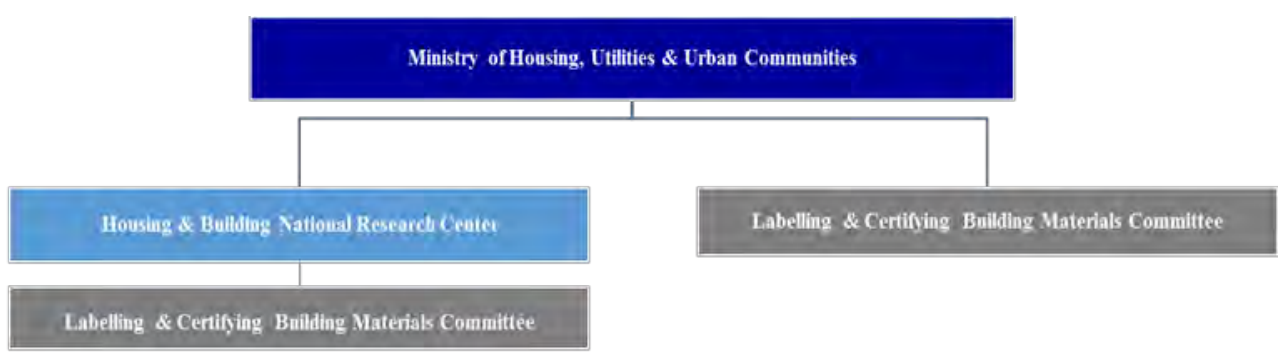

The newly proposed committees

Fig. (3): The Structure of the Proposed System

Source: The Researcher

- The Technical Steering Committee of Green Building Materials: The role of The Technical Steering Committee of Green Building Materials is as shown in Fig. (2).

- Labeling \& Certifying Building Materials Committee: It is a non-profit interest committee. The goal of the committee is to inform consumers by all necessary data about the green building materials thereby giving support to material-related health \& environmental protection. Labels \& Certifications are "licensed" for use only after a material is proven to meet transparent, published standards for sustainable preferability developed by the established Technical Steering Committee of Green Building Materials and verified by a qualified, independent, third party, which is the Labelling \& Certifying Building Materials Committee and assessed over multiple environmental parameters (not just one single issue). 
The ecolabels and the certifications are an assurance to consumers and professionals that a material is proven "green" and has high environmental values and integrity.

- The Stages of the Proposed System: Based on the process of green building material assessment, there are three basic stages for the proposed system as shown in Fig. (2).

\section{Research}

Information is a crucial ingredient for all this work. An incredible amount of information about building materials is necessary. The system aims to provide the descriptions of each building material available in the Egyptian market and the protocols through which they are evaluated.

This stage involves collecting \& gathering all available technical information about building materials in the local market from all currently available resources as mentioned before to be evaluated.

\section{Second Stage: Evaluation}

This stage involves filling in information gaps, completing missing \& incomplete about building materials in the Egyptian market through in-depth research as well as confirmation of the technical information by the Technical Steering Committee of Green Building Materials. Once research and information gathering are complete, evaluation can begin. Evaluation and assessment criteria can be accomplished by comparing similar types of building materials based on the environmental \& health impacts and the economic performance of the building materials.

- Technical support: Gives the technical support for building materials companies and co-operate with the Egypt National Cleaner Production Centre as it has already taken steps to support the Egyptian chemical building materials companies in order to:

- Comply with registration requirements of the European Union regulation concerning the Registration, Evaluation, Authorization, and restriction of Chemicals (REACH) otherwise, these companies will not be able to further export their chemicals for the EU market.

- Help these companies with the preparation of Safety Data Sheets.

- To comply with the requirements of EU directive of Classification, Labelling and Packaging (CLP) of Chemicals.

- Setting regulations \& standards: Setting regulations \& standards for building materials with a very high concern which directly or indirectly affect our health and the environment using prescriptive and performance-related provisions. This applies to substances that cause cancer, infertility, genetic mutations or birth defects, and to those which are persistent and accumulate in the environment. Regulations would address specific issues as:

- Having readily available information on the hazardous properties of human health and the environment and identifying groups who are potentially exposed to these hazards including workers, consumers, and the public.

- Recommended control measures, allows the production, transport, use, and disposal of these materials to be managed safely.

- Setting references \& benchmarks

Setting references \& benchmarks (minimum mandatory requirements) for building materials specifications in Egypt to safeguard the environment, public health, safety and general welfare and to reduce the negative impacts and increase the positive impacts of the built environment on the natural environment and building occupants.

Reference Values \& Benchmarks (minimum mandatory requirements) can be expressed as "not-to-exceed" levels, that is, levels of a toxic substance in air that do not exceed a critical value that is usually based on levels that affect animals; they are then adjusted to levels that will help protect humans.

As mentioned before approved international reference values \& benchmarks related to human health could only be applied worldwide but for that related to the manufacturing process, use and all other factors cannot be directly used without being adapted, tested and verified to be locally applied.

\section{- $\quad$ Testing of building materials}

Test methods should be defined. Product tests may only be conducted by a test laboratory or institute accredited according to ISO 17025 and approved by the Technical Steering Committee of Green Building Materials which provides names of accredited testing institutions on request.

\section{- Confirmation \& evaluation of the technical information}


Confirmation \& evaluation of the technical information collected in the first stage including information provided by manufactures, material's warranty and durability test information, MSDS and IAQ test data from independent laboratories.

\section{- Setting Evaluation Criteria for Green Building Materials}

Evaluation of green building materials is a challenging task. There is no common definition and criteria to follow, different experts evaluate materials from different perspectives.

As there seems to be a lot of confusion about designating any material as a green material, efforts are on to develop integrated evaluation criteria which can help in the evaluation of the sustainability \& performance of green building materials.

The process of setting criteria for the evaluation of green building materials is based on science, not assumptions and on a comprehensive assessment protocol, tests, and analysis that addresses the impacts of the material through the whole life cycle (cradle to grave or cradle-to-cradle). At each stage, the consumption of natural resources including non-renewable energy, pollution \& waste produced and the cost is considered. Figure (4) shows the inputs and outputs of the main three stages of the life cycle of a green building material: Manufacturing \& Construction Stage, In-Use Stage, and End of Life Stage.

Impacts to analyze at each phase:

- Natural resources consumed including non-renewable energy and water.

- Waste \& Pollutants result from each phase including air, water, and soil pollutants.

- Cost of each stage (Life Cycle Cost Assessment (LCC)).

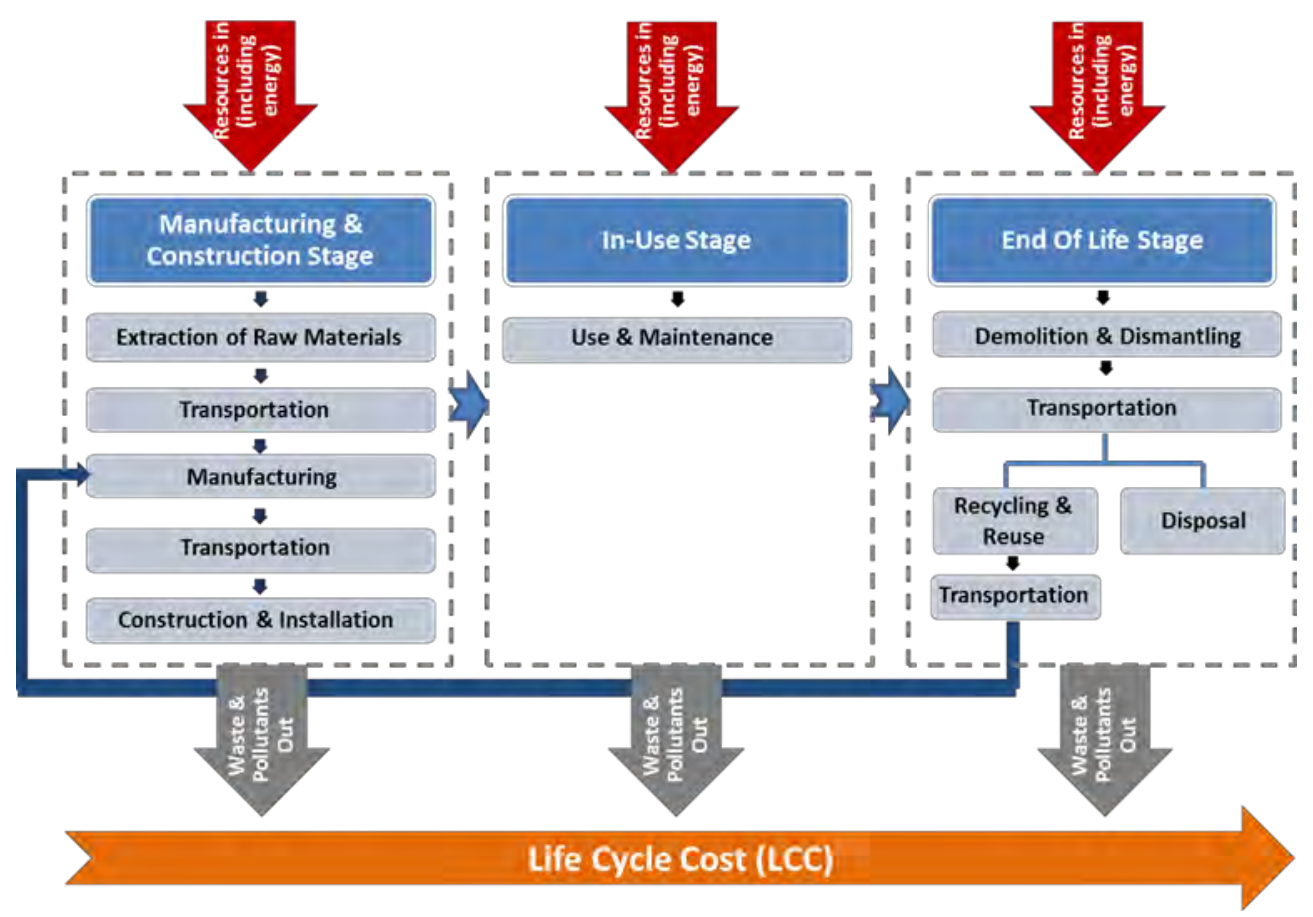

Fig. (4): A Graph Showing the Inputs \& Outputs of the Main three Stages of the Life Cycle of a Green Building Material Source: The Researcher

Each evaluation criterion would evaluate the performance of each material towards the three pillars of sustainability (Environmental, Social \& Economic) as shown in Table (1). The evaluation criteria can be classified according to the material's life cycle stage in which the impacts of each criterion could be identified, as shown in Table (1), into four main groups:

- Evaluation Criteria in the Manufacturing \& Construction Stage.

- Evaluation Criteria in the In-Use Stage.

- Evaluation Criteria at the End of Life Stage.

- Evaluation Criteria for the Whole Life Cycle. 


\subsection{The Whole Integrated Life Cycle Assessment}

The process of determining exactly how green specific materials, is very complicated. There is a complexity of variables that contribute to the green-ness of a material. As long as a material has at least one positive impact whether on the environment, health or the economy, it could be defined as green. However, when analyzed more carefully, this same material could actually be harming more than it is helping. This means that this building material has negative impacts more than its positive impacts as we had mentioned before.

That's why on developing the new system for the whole integrated life cycle assessment of green building materials, their environmental, social and economic impacts should be considered over the whole life (Pros and Cons).

The whole integrated life cycle assessment is based on comprehensive environmental assessment protocol that determines the key performance indicators \& establishes measurable evaluation criteria for the evaluation of green building materials throughout the whole lifecycle.

The Whole Integrated Life Cycle Assessment involves the use of an evaluation matrix for scoring the material-specific environmental, health \& economic impacts. The total score of each material represents the material's green attributes and its contribution towards sustainability.

Depending upon project-specific goals, an assessment of green materials may involve an evaluation of one or more of the criteria listed below in Table (1).

\section{- New Scoring System}

Based on the reference values and benchmarks developed by the Technical Steering Committee of Green Building Materials each criterion will be given a maximum number of possible points and the assigning rating to each criterion must be approved by focus groups from national and international experts. Each material will assign certain rating to each criterion depending on the positive and negative environmental, social and economic impacts of this material, the positive impacts will be given + ve points meanwhile the negative impacts will be given - ve points as shown in Table (1), the overall evaluation of the material can be made by summation of score obtained by this material in these ratings.

Table 1. The Evaluation Matrix for the Whole Integrated Life Cycle Assessment

\begin{tabular}{|c|c|c|c|c|c|c|c|c|c|}
\hline \multirow[t]{2}{*}{ Stage } & \multirow[t]{2}{*}{ Evaluation Criteria } & \multicolumn{2}{|c|}{$\begin{array}{c}\text { Ecological } \\
\text { impacts }\end{array}$} & \multicolumn{2}{|c|}{$\begin{array}{l}\text { Social \& } \\
\text { Health } \\
\text { impacts }\end{array}$} & \multicolumn{2}{|c|}{$\begin{array}{c}\text { Economic } \\
\text { impacts }\end{array}$} & \multirow{2}{*}{$\begin{array}{l}. \stackrel{0}{\Xi} \\
0 \\
0 \\
0 \\
\frac{0}{0} \\
00 \\
0 \\
0\end{array}$} & \multirow{2}{*}{ 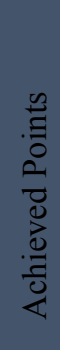 } \\
\hline & & $\begin{array}{c}\text { Pros } \\
+ \text { ve } \\
\text { Points }\end{array}$ & $\begin{array}{l}\text { Cons } \\
\text {-ve } \\
\text { Points }\end{array}$ & $\begin{array}{c}\text { Pros } \\
+ \text { ve } \\
\text { Points }\end{array}$ & $\begin{array}{l}\text { Cons } \\
\text {-ve } \\
\text { Points }\end{array}$ & $\begin{array}{c}\text { Pros } \\
+ \text { ve } \\
\text { Points }\end{array}$ & $\begin{array}{c}\text { Cons } \\
\text {-ve } \\
\text { Points }\end{array}$ & & \\
\hline \multirow{8}{*}{ 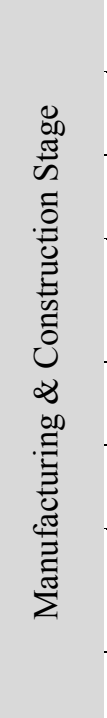 } & Local Availability & & & & & & & & \\
\hline & Embodied Energy & & & & & & & & \\
\hline & Recycled Content & & & & & & & & \\
\hline & $\begin{array}{c}\text { Rapidly renewable } \\
\text { materials }\end{array}$ & & & & & & & & \\
\hline & Material Toxicity & & & & & & & & \\
\hline & Pollutants Emissions & & & & & & & & \\
\hline & $\begin{array}{c}\text { Resource efficient } \\
\text { manufacturing process }\end{array}$ & & & & & & & & \\
\hline & Ease of Installation & & & & & & & & \\
\hline$\stackrel{\dot{E}}{\leftrightarrows}$ & Material Toxicity & & & & & & & & \\
\hline
\end{tabular}




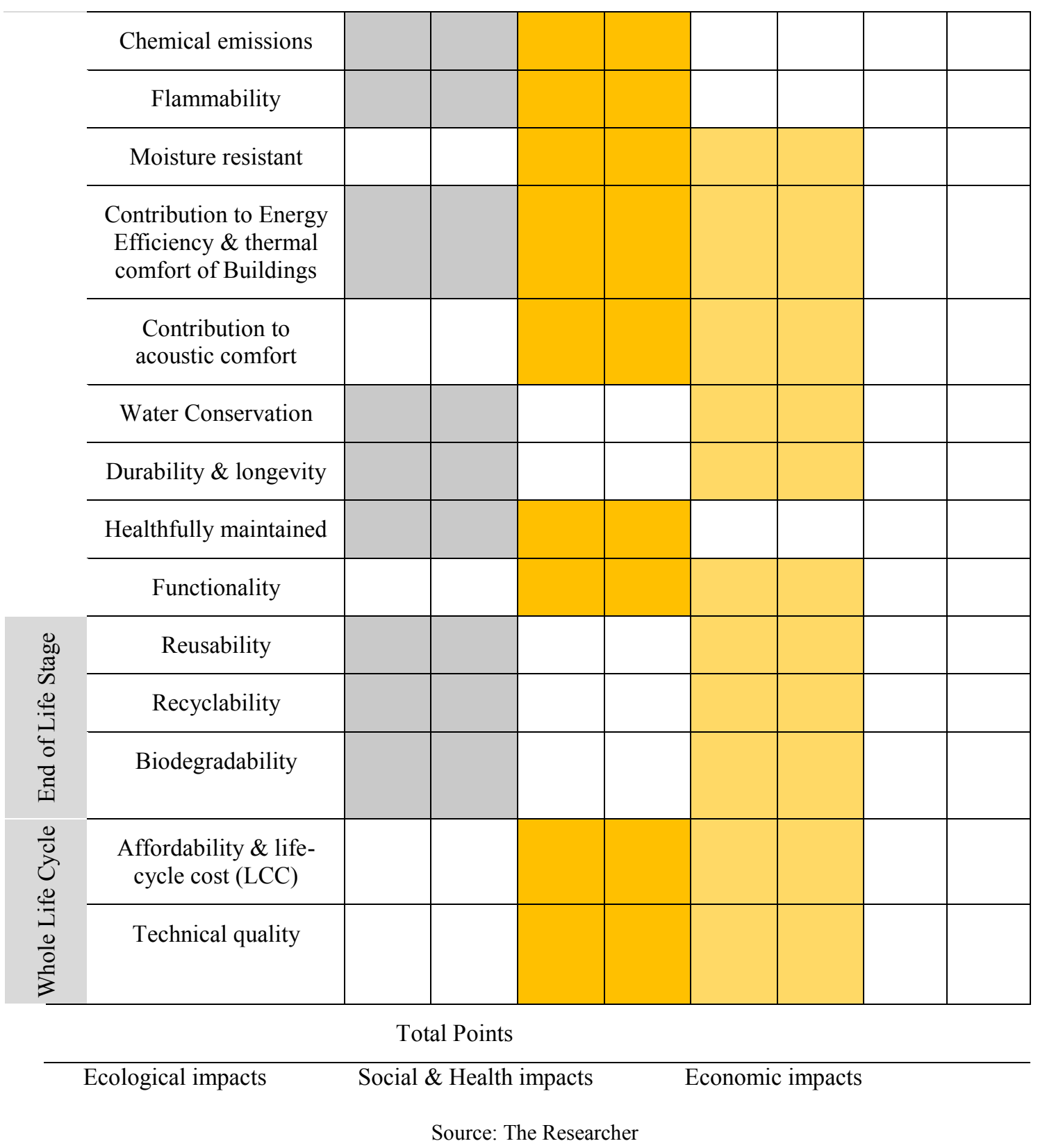

\section{- Classification of materials based on scale}

After evaluating the material for and allocating points for each criterion totaling maximum to 100 points, materials can be classified based on total points scored, as shown in Table (2). 


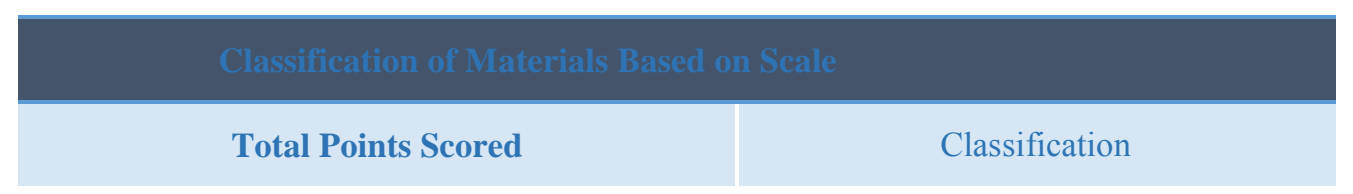

70

Total Green Material

\begin{tabular}{c|c}
$\mathbf{7 0 - 3 0}$ & Intermediate materials \\
\hline 30 & Not a green material \\
\hline
\end{tabular}

\section{- Developing the Egyptian System for Classification}

The Proposed Egyptian System of Classification Building Materials is a system for harmonizing the classification of Building Materials. It is a logical and comprehensive approach to create classification processes that use developed benchmarks in order to define environmental, health \& physical hazards and the economic impacts of building materials.

The role of the classification system is developing classification criteria for building materials for distinguishing material groups with certain common features.

The classification system classifies green building materials according to their characteristics in classes. The classification system is based on a defined analytical test method and defined classification criteria.

\section{- Labelling \& Certification of green building materials}

Labelling \& Certification are voluntary procedures that assess, audit and give a written assurance that a material meets specific standards. Labelling awards marketable logos meanwhile certification awards certificates (Third-party certification).

Labelling \& Certification are performed by the Labeling \& Certifying Building Materials Committee which is a neutral, independent third party that evaluates the compliance of the building material with the clearly defined standards established by the Technical Steering Committee of Green Building Materials and materials should meet or exceed baseline standards and the benchmarks established by this committee. Labelling \& Certification are often used to substantiate specific attributes of building material. The Labeling \& Certifying Building Materials Committee applies credible certification programs based on third-party assessment and allows the participation of all significantly concerned parties.

\section{- Developing Green Building Material Declaration Sheets \& Establishing Material Directive}

Green Building Material declaration is a format for full specifications of green building materials for sales and marketing purposes that reports mate-rial content and associated environmental, health and economic information related to individual building materials.

It is a tool for the accurate reporting of the product contents and each ingredient's relationship to the bigger picture of ecological \& human health and economic impacts. These impacts should be evaluated on a cradle-to-cradle basis. The Declaration comprises in detail:

- General information: Product characteristics, material definition and physical construction data, details on base materials and material origin, description of the material manufacturing process, information on material processing, data on the utilization status, extraordinary effects and re-use phase.

- $\quad$ Results of the Whole Integrated Life Cycle Assessment.

- Documentation and tests.

- Health hazards from both direct exposure to a substance and from the substances that may be used or created throughout the life cycle and personal protection during manufacturing.

- Risk and safety management.

- Guidelines for demolition, Construction and maintenance management.

- Manuals, warranties, common instructions.

- After the development of Green Building Material Declaration Sheets comes the establishment of Material Directive for all existing active substances and systematic review will be fed. The Material Directive represents a cornerstone for the establishment of the digital library. 


\section{Selection}

The main aim of this stage is to help those involved in the design, construction, and management of buildings in Egypt to reach their sustainability goals $\&$ to drive sustainable change. For designers, the process of product selection begins after the establishment of project-specific environmental goals. Green building materials selection is based on the material that best meets the established evaluation criteria and the project's goals

To ease the process of selection of green building materials \& the online assessment, the establishment of a digital database for green building materials \& a web-based resource guide for green building materials based on the development of software and a digital library for all building materials available in the Egyptian market became a necessity.

\section{- Green Building Materials Software \& Digital Library}

In order to make a shift towards sustainability, green building materials information has to exist in a form that could be easily accessible to those who need it, without a lot of research or effort. For that reason, the Technical Steering Committee of Green Building Materials has to develop software \& a digital library to make sustainability goals measurable and actionable using: facts, collected data, the developed Whole Integrated Life Cycle Assessment \& Green Building Material Declaration Sheets to create value from sustainability and drive sustainable change.

The development of software \& a digital library could be made possible with the aid of Information Technology (IT) department at the Technical Steering Committee of Green Building Materials. The software would be user-friendly software that can be freely downloaded on the Web site of this committee. This publicly available database allows users and any member of the project team to download all the necessary information about any locally used building material and to objectively review and compare analysis results that are based on data collection and analysis methods.

The digital library would be an access to a wealth of resources and an online catalog for material selection: lists of building materials and components that have been assessed in terms of their environmental, health \& economic impacts across their entire life cycle - from 'cradle to grave' or 'cradle to cradle,' transparent and in-depth information about building materials, with comparative scores on environmental, health and cost impacts that helps users to make better choices for sustainable development. Detailed information about different building materials in the Egyptian Market should be profiled and can be automatically screened through browsing dozens of material categories, or using search filters to specify material criteria.

In addition, each region would have a reference code, the Find Function could be used to locate a particular region and its reference code and the online system automatically determines all available green building materials in that region and their specifications based on the selected region.

\section{- Benefits of developing the software \& the digital library for green building materials}

- Making search easy \& simple.

- Encourage the use of Building Materials with verified health and environmental attributes.

- Access full green building materials profiles, research helps identify the full range of the project's building material options.

- Users could easily browse; search and filter for the building materials that best fit the project goals.

- Search for the best products with the lowest impacts.

- $\quad$ Find material by name, category, keyword, regional code or manufacturer through search.

- Evaluate, compare and assess similar green building materials in like categories.

- Easily compare materials' Pros and Cons that are highlighted for easy comparison.

- Scoring details link to transparent scoring protocols developed for the whole integrated life cycle assessment.

- Users could save building materials and searches for their individual, companies, or projects' libraries.

- For comparing hazards from different materials, color coding would be developed to indicate the prioritization of concern based on the type of hazard and the degree of scientific evidence.

There will be always updating for all technical innovations and any new data will be added to the database to cope with innovative approaches and alternative materials, designs, and methods. 


\section{Conclusion}

It can be concluded that the process of developing a digital database for green building materials in Egypt even if it seems to be a very complex issue, but it is essential for building new cities for the future and for the sake of the future generations. In order to make a shift towards sustainability, information about green building materials has to exist in a form that could be easily accessible to designers, constructors, and developers, without a lot of research or effort. Easily updateable directories and website database should be developed. With the growth of information technologies (ITs), the potential of dealing with vast quantities of information became an essential tool to reduce the negative impacts of building materials.

\section{Future implementation}

Other criteria can also be investigated concerning the sustainability of green building materials. These criteria can be social, political, ethical \& spiritual which needs the examination of possible social, technological, and health implications at every stage of the life cycle of the building materials and every sector of society.

\section{References}

1. AgBB (Committee for Health-related Evaluation of Building Products) (2012). Evaluation procedure for VOC emissions from building $\begin{array}{lcccc}\text { products. } & \text { Retrieved } & \text { April } & 16, & 2012 \\ \text { http://www.umweltbundesamt.de/sites/default/files/medien/355/dokumente/agbb evaluation } & \text { scheme } & 2012 & 0 . p d f .\end{array}$

2. Fithian, C. \& Sheets, A. (2009). Green Building Materials-Determining the True Definition of Green. Retrieved August 1, 2016, from https://repositories.lib.utexas.edu/bitstream/handle/2152/13325/9-Fithian_Sheets-Green_Building_Materials.pdf?sequence=2\&isAllowed=y.

3. Froeschle, L.M. (1999). Environmental Assessment and Specification of Green Building Materials. The Construction Specifier, October 1999, 53-57. Retrieved September 9, 2016, from http://www.calrecycle.ca.gov/GreenBuilding/Materials/CSIArticle.pdf.

4. German Sustainable Building Council. DGNB Certification System. Retrieved January 15, 2015, from http://www.dgnbsystem.de/en/system/certification_system/.

5. Isnin, Z., Ahmad, S.S. \& Yahya, Z. (2012). Building Material Management Framework for Greener Adaptation Projects. Asian Journal of Environment-Behaviour Studies, Volume 3, Number 8, 45-54. Retrieved September 7, 2016, from https://fspu.uitm.edu.my/cebs/images/stories/cebs/ajebsv4n122013c4.pdf.

6. Mehta, G., Mehta, A. \& Sharma, B. (2014). Selection of Materials for Green Construction: A Review. Journal of Mechanical and Civil Engineering, Volume 11, Issue 6 Ver. III, 80-83. Retrieved September 7, 2016, from www.iosrjournals.org.

7. Milani, B., (2001). Building Materials in a Green Economy Community-based Strategies for Dematerialization.The biennial conference of the Canadian Society for Ecological Economics (CANSEE), McGill University, Montreal. Retrieved September 1, 2016, from http://www.greeneconomics.net/BuildMatEssay.html.

8. Spiegel, R. and Meadows D. (1999), Green Building Materials: A Guide to Product Selection and Specification, John Wiley \& Sons, Inc., New York.

9. Thomas, D.R. (2006). A General Inductive Approach for Analyzing Qualitative Evaluation Data. Journal of Evaluation June 2006 vol. 27 no. 2 237-246. Retrieved October 1, 2016, from http://legacy.oise.utoronto.ca/research/field-centres/ross/ctl1014/Thomas2006.pdf. DOI: $10.1177 / 1098214005283748$.

10. Umar, U.A., Tukur, H., Khamidi, M.F. \& Alkali, A.U. (2012). Impact of Environmental Assessment of Green Building Materials on Sustainable Rating System. Retrieved September 9, 2016, from https:/www.researchgate.net/publication/233996916. DOI: 10.4028/www.scientific.net/AMR.689.398. 